\title{
FORMAÇÃO E ESTABILIZAÇÃO DE AGREGADOS DO SOLO DECORRENTES DA ADIÇÃO DE COMPOSTOS ORGÂNICOS COM DIFERENTES CARACTERÍSTICAS HIDROFÓBICAS ${ }^{(1)}$
}

\author{
Renato Saldanha Bastos ${ }^{(2)}$, Eduardo de Sá Mendonça(3), \\ Víctor Hugo Alvarez V.(3) \& Marcelo Metri Corrêa(4)
}

\begin{abstract}
RESUMO
Substâncias orgânicas podem favorecer o aumento da estabilidade de agregados, reduzindo, de acordo com seu grau de hidrofobicidade, a velocidade de infiltração de água nos agregados. Este trabalho teve como objetivo estudar a formação e estabilização de agregados de um Latossolo Vermelho-Amarelo distrófico em virtude da adição de compostos orgânicos com características hidrofóbicas e hidrofílicas distintas. Foram incubados $100 \mathrm{~g}$ de TFSA do horizonte A e do B com diferentes doses de três compostos orgânicos: ácido esteárico P.A., amido P.A. e ácido húmico purificado de acordo com a Sociedade Internacional de Substâncias Húmicas. $O$ experimento foi realizado com os tratamentos gerados de acordo com a matriz Plan-Puebla III modificada, com as doses do espaço experimental variando de -0,55 a 10,45 $\mathrm{g} \mathrm{kg}^{-1}$. Após o período de 160 dias de incubação, avaliaram-se: o índice de estabilidade de agregados, 0 diâmetro médio ponderado e o diâmetro médio geométrico dos agregados formados. Os resultados indicaram que compostos orgânicos com caráter hidrofílico dominante não têm influência na formação e estabilização de agregados do solo, principalmente quando se usam doses até $9,9 \mathrm{~g} \mathrm{~kg}^{-1}$. Observouse, também, que a aplicação de moléculas orgânicas com acentuado caráter hidrofóbico e hidrofílico na sua estrutura, como os ácidos húmicos, é capaz de melhorar a agregação de solos com grau de intemperismo avançado.
\end{abstract}

Termos de indexação: amido, ácido esteárico, substancias húmicas, solos tropicais.

\footnotetext{
(1) Trabal ho extraído da Tese de Mestrado do primeiro autor, em Sol os e Nutrição de Plantas pela U niversidade F ederal de Viçosa UFV. Recebido para publicação em setembro de 2003 e aprovado em outubro de 2004.

(2) Mestre em Solos e Nutrição de Plantas pela Universidade Federal de Viçosa- UFV. Departamento de Solos, CEP $36570-000$ Viçosa (MG).

(3) Professor do Departamento de Solos, UFV. E-mails: esm@ufv.br; vhav@ufv.br

(4) Doutorando em Solos e Nutrição de Plantas, Departamento de Solos, UFV. E-mail: marcelometri@yahoo.com
} 


\title{
SUMMARY: SOIL AGGREGATE FORMATION AND STABILIZATION AS INFLUENCED BY ORGANIC COMPOUNDS WITH DIFFERENT HYDROPHOBIC CHARACTERISTICS
}

\begin{abstract}
According to their hydrophobi city degree, organic substances can increasetheaggregate stability, reducing therate of water infiltration into theaggregates. Our study investigated the aggregate genesis and stabilization in a Red-Yellow Latosol under organic compound addition with distinct hydrophobic and hydrophilic characteristics. Air-dried samples from the $A$ and $B$ horizons were incubated with different doses of three organic compounds: estearic acid, amid and humic acid purified in accordance to the International Humic Substances Society. The experiment was organized with the treatments according to the modified Plan-Puebla III matrix, using doses varying from -0.55 to $10.45 \mathrm{~g} \mathrm{~kg}^{-1}$ in the experimental range After 160 days of incubation, theaggregatestability index, mean weight diameter, and themean geometric diameter of theaggregates formed weremeasured. Results indicatethat theaddition of organic compounds with dominant hydrophilic character does not influencethesoil aggregategenesis and stabilization, mainly in doses up to $9.90 \mathrm{~g} \mathrm{~kg}^{-1}$. Theaddition of organic molecules with a hydrophobic and hydrophilic structurecharacter, such as humi c acids, is able to improve aggregati on in soils with a high weathering degree.
\end{abstract}

Index terms: amid, estearic acid, humic substances, tropical soils.

\section{INTRODUÇÃO}

Vários estudos têm enfocado o uso de materiais orgânicos para mel horar a agregação do solo, visto que as substâncias húmicas, principalmente os ácidos húmicos, têm efeito benéfico na estabilidade dos agregados do solo (Tisdall \& Oades, 1982; Lynch \& Bragg, 1985; Fortun et al., 1990; Piccolo \& Mbagwu, 1990, 1994).

Dois são os principais mecanismos envolvidos no aumento da estabilidade dos agregados pela ação da matéria orgânica do solo. O primeiro pela formação de ligações de materiais orgânicos com as partículas minerais ou pela ação física de raízes ou hifas de fungos (Tisdall \& Oades, 1982; Chenu et al., 1994). O segundo é a ação da matéria orgânica do solo na diminuição da entrada de água no agregado, reduzindo, assim, sua quebra pela expulsão instantânea do ar. Este último processo é também conhecido como repelência à água ou hidrofobicidade do agregado (Sullivan, 1990).

As substâncias orgânicas, quando adicionadas a determinados solos, podem expressar severa repelência à água. Esta hidrofobicidade pode ser notada tanto em solos arenosos (Bond, 1969; Wallis $\&$ Horne, 1992) como em sol os argil osos (Macghie \& Posner, 1980). Várias frações orgânicas são consideradas responsáveis pela hidrofobicidade dos solos, tais como: ácidos húmicos, frações alifáticas ou, ainda, resíduos vegetais (Chenu et al., 2000).

As substâncias húmicas podem ser divididas, conforme sua afinidade com água, em: hidrofílicas, constituídas principalmente por carboidratos neutros ou ácidos de origem microbiana e derivados de plantas, e hidrofóbicas, formadas por cadeias carbônicas longas, alifáticas e ricas em polifenóis oriundos principalmente da oxidação da lignina e da celulose (Kaiser \& Zech, 2000). Contudo, as substâncias húmicas não são exatamente polímeros, podendo ser consideradas moléculas pequenas ligadas por forças hidrofóbicas, que são facilmente separadas, quando tratadas com ácidos orgânicos (Piccolo et al., 1996; Conte \& Piccolo, 1999). Pela ligação de argila-metal-substância húmica, a porção hidrofílica da matéria orgânica orienta-sena direção do interior dos agregados, enquanto a porção hidrofóbica direciona-se para a face externa, formando, assim, uma camada repelente à água. Essa camada, por sua vez, reduz a possibilidade de desestruturação do solo pela expulsão rápida do ar (J onge et al., 1999; Piccolo \& M bagwu, 1999).

Segundo Haynes \& Swift (1990) e Dinel et al. (1991a; 1991b; 1992), compostos orgânicos alifáticos, com al to conteúdo de C, de caráter hidrofóbico, são responsáveis pela estabilidade de agregados. A distribuição não-uniforme da matéria orgânica hidrofóbica irá retardar a entrada de água nos agregados, aumentando a resistência del es quando expostos à água (Sullivan, 1990). A implicação prática dessa observação é que o tratamento do solo com materiais orgânicos, que contenham quantidades substanciais de compostos hidrofóbicos, estabilizará os agregados do solo, mais do que compostos com predominância de materiais hidrofílicos.

O objetivo deste trabalho foi estudar a formação e estabilização de agregados de solo tropical de acordo com a adição de compostos orgânicos com características hidrofóbicas e hidrofílicas distintas.

\section{MATERIAL E MÉTODOS}

Foram coletadas amostras dos horizontes A (0$20 \mathrm{~cm})$ e B $(40-60 \mathrm{~cm})$ de um Latossolo Vermel hoAmarelo distrófico (LVAd) da região de Viçosa, Minas Gerais (Quadro 1). 
O composto orgânico de caráter hidrofóbico utilizado nos tratamentos foi o ácido esteárico puro ( $\mathrm{E}$, ácido octadecanóico $-\mathrm{CH}_{3}\left(\mathrm{CH}_{2}\right)_{16} \mathrm{COOH}$ ), usado para a texturação de fol has de alumínio e fabricado

Quadro 1. Caracterização química e física de amostras de material de solo de dois horizontes de um L atossolo Vermelho-Amarelo de Viçosa, MG

\begin{tabular}{|c|c|c|}
\hline Característica & Horizonte A & Horizonte B \\
\hline $\mathrm{pH} \mathrm{H} \mathrm{H}_{2} \mathrm{O}(1: 2,5)$ & 4,20 & 5,00 \\
\hline $\mathrm{pH} \mathrm{KCl}(1: 2,5)$ & 4,00 & 5,24 \\
\hline$P\left(\mathrm{mg} \mathrm{dm}^{-3}\right)^{(1)}$ & 0,90 & 0,40 \\
\hline$K\left(\mathrm{mg} \mathrm{dm}^{-3}\right)^{(1)}$ & 18,00 & 7,00 \\
\hline $\mathrm{Ca}^{2+}\left(\mathrm{cmol}_{\mathrm{c}} \mathrm{dm}^{-3}\right)^{(2)}$ & 0,18 & 0,05 \\
\hline $\mathrm{Mg}^{2+}\left(\mathrm{cmol}_{\mathrm{c}} \mathrm{dm}^{-3}\right)^{(2)}$ & 0,06 & 0,05 \\
\hline $\mathrm{Al}^{3+}\left(\mathrm{cmol}_{\mathrm{c}} \mathrm{dm}^{-3}\right)^{(2)}$ & 1,15 & 0,00 \\
\hline $\mathrm{H}+\mathrm{Al}\left(\mathrm{cmol}_{\mathrm{c}} \mathrm{dm}^{-3}\right)^{(3)}$ & 8,43 & 1,65 \\
\hline $\mathrm{SB}\left(\mathrm{cmol}_{\mathrm{c}} \mathrm{dm}^{-3}\right)$ & 0,29 & 0,12 \\
\hline $\mathrm{t}\left(\mathrm{cmol}_{\mathrm{c}} \mathrm{dm}^{-3}\right)$ & 1,44 & 0,12 \\
\hline $\mathrm{T}\left(\mathrm{cmol}_{\mathrm{c}} \mathrm{dm}^{-3}\right)$ & 8,72 & 1,77 \\
\hline V (\%) & 3,32 & 6,78 \\
\hline $\mathrm{m}(\%)$ & 79,80 & 0,00 \\
\hline $\mathrm{CO}\left(\text { dag } \mathrm{kg}^{-1}\right)^{(4)}$ & 3,21 & 0,26 \\
\hline Areia Grossa (\%) (5) & 17,50 & 13,00 \\
\hline Areia Fina (\%) (5) & 11,50 & 10,00 \\
\hline Silte (\%) ${ }^{(5)}$ & 6,50 & 5,50 \\
\hline Argila (\%) (5) & 64,50 & 71,50 \\
\hline
\end{tabular}

por Chinie Test. O composto orgânico de caráter hidrofílico foi o amido solúvel P.A. (Am, $\mathrm{C}_{6} \mathrm{H}_{12} \mathrm{O}_{6}$ com ligações a 1-4), cujo fabricante é Labsynth. As características intermediárias de hidrofobicidade foram representadas por um ácido húmico $(\mathrm{AH})$ extraído de um Espodossolo da região de Lavras Novas, purificado e dialisado, segundo a técnica recomendada pela Sociedade I nternacional de Substâncias Húmicas - IHSS (Swift, 1996).

Para a realização do trabal ho, $100 \mathrm{~g}$ deTFSA foram colocados em potes plásticos com tampa de volume aproximado de $250 \mathrm{~mL}$. Todos os compostos foram adicionados em pó ao solo seco e homogeneizados. E $\mathrm{m}$ seguida, adicionou-se em cada pote água deionizada até atingir $80 \%$ da capacidade de campo (29,36 dag kg-1 no horizonte A, e 30,48 dag kg-1, no horizonte B) de seu respectivo horizonte.

Avaliaram-se as respostas às doses aplicadas dos compostos orgânicos (Quadro 2), sozinhos ou em combinação.

O experimento foi realizado com os tratamentos gerados para três fatores, de acordo com a matriz Plan-Puebla III modificada (Turrent \& Laird, 1975), com as doses do espaço experimental variando, para os três fatores, de -0,55 a 10,45 $\mathrm{g} \mathrm{kg}^{-1}$, e dispostos em del ineamento intei ramente casualizado com três repetições (Quadro 2 ). O intervalo de tempo de incubação foi de 160 dias, e os potes foram mantidos em uma incubadora deDBO a $25^{\circ} \mathrm{C}$. A pós otérmino do período de incubação, as unidades experimentais foram retiradas da incubadora e os recipientes deixados abertos durante dez dias, a fim de que estas atingissem o equilíbrio com a umidade atmosférica.

Quadro 2. Doses de compostos secos utilizados para serem misturados às amostras de TFSA para consti tuição dos tratamentos para o estudo de formação e estabi lização de agregados de um Latossolo Vermelho-Amarelo de Viçosa, MG

\begin{tabular}{|c|c|c|c|c|c|}
\hline \multicolumn{3}{|c|}{ Tratamento(1) } & Amido & Ácido esteárico & Ácido húmico \\
\hline$-0,9$ & $-0,9$ & $-0,9$ & 0,00 & 0,00 & 0,00 \\
\hline$-0,4$ & $-0,4$ & $-0,4$ & 2,75 & 2,75 & 2,75 \\
\hline$-0,4$ & $-0,4$ & 0,4 & 2,75 & 2,75 & 7,15 \\
\hline$-0,4$ & 0,4 & $-0,4$ & 2,75 & 7,15 & 2,75 \\
\hline$-0,4$ & 0,4 & 0,4 & 2,75 & 7,15 & 7,15 \\
\hline 0,4 & $-0,4$ & $-0,4$ & 7,15 & 2,75 & 2,75 \\
\hline 0,4 & $-0,4$ & 0,4 & 7,15 & 2,75 & 7,15 \\
\hline 0,4 & 0,4 & $-0,4$ & 7,15 & 7,15 & 2,75 \\
\hline 0,4 & 0,4 & 0,4 & 7,15 & 7,15 & 7,15 \\
\hline$-0,9$ & $-0,4$ & $-0,4$ & 0,00 & 2,75 & 2,75 \\
\hline$-0,4$ & $-0,9$ & $-0,4$ & 2,75 & 0,00 & 2,75 \\
\hline$-0,4$ & $-0,4$ & $-0,9$ & 2,75 & 2,75 & 0,00 \\
\hline 0,9 & 0,4 & 0,4 & 9,90 & 7,15 & 7,15 \\
\hline 0,4 & 0,9 & 0,4 & 7,15 & 9,90 & 7,15 \\
\hline 0,4 & 0,4 & 0,9 & 7,15 & 7,15 & 9,90 \\
\hline 0,0 & 0,0 & 0,0 & 4,95 & 4,95 & 4,95 \\
\hline
\end{tabular}

\footnotetext{
(1) Matriz Plan Puebla III modificada, $1+2^{k}+2 k+1$, em que $k=3$ fatores.
} 


\section{Variáveis morfológicas avaliadas por via seca}

Para avaliar a estabilidade de agregados por via seca, foi utilizado o método indireto de penei ramento a seco. Este procedimento foi efetuado para a separação inicial dos agregados formados. Foram utilizados duas peneiras $(4,00$ e $2,00 \mathrm{~mm})$ e um vibrador Produtest, agitando-se a amostra durante 5 min, na graduação no 5 do aparelho. A seguir, uma parte de cada fração foi seca em estufa a $105^{\circ} \mathrm{C}$ para correção de seu peso. Assim, foram calculados o diâmetro médio ponderado (DMP) e o diâmetro médio geométrico (DMG), segundo equações propostas por Kemper \& Chepil (1965),

$$
\text { DMP }=\sum_{i=1}^{n} x_{i} d_{i} \quad e^{D M G}=10^{i=1} \sum_{i}^{n} x_{i} \log d_{i}
$$

sendo $x_{i}=$ quociente da massa de agregados retidos na peneira i sobre a massa total; $d_{i}=$ diâmetro médio da fração.

\section{Variáveis morfológicas avaliadas por via úmida}

$\mathrm{Na}$ avaliação da estabilidade de agregados por via úmida, foram usados $20 \mathrm{~g}$ de solo. A amostra foi pré-umedecida, conforme o princípio de umedecimentolento, descrito por Kemper \& Chepil (1965). Depois desse pré-umedecimento, a amostra foi mantida em repouso à temperatura ambiente por 30 min. Logo em seguida, essa amostra foi posta no aparel ho de oscilação vertical sobre um conjunto de peneiras de 2,00; 1,00; 0,50; 0,25 e 0,105 mm de diâmetro, conforme descrito por Yoder (1936). Transcorridos $15 \mathrm{~min}$, as porções retidas em cada peneira foram transferidas para cápsulas de alumínio com o auxílio de jatos de água, e secas em estufa a $105^{\circ} \mathrm{C}$ por um período de $24 \mathrm{~h}$ para posterior pesagem. A partir dos valores dessas massas, calcularam-se o DMP, o DMG e o índice de estabilidade de agregados (IEA) (Kemper \& Chepil, 1965).

A análise estatística foi feita por regressão. A significância das equações foi testada pelo teste $F$ ( $P<0,10, P<0,05, P<0,01$ e $P<0,001)$. As equações foram estimadas com o auxílio do programa SAS (Statistical Analysis System) versão 8.0 e as superfícies de respostas plotadas com o auxílio do programa STATISTICA versão 6.0.

\section{RESULTADOS E DISCUSSÃO}

Como os fatores estudados foram três: amido $(A m)$, ácido esteárico $(E)$ e ácido húmico $(A H)$, para conseguir representar seu volume de resposta utilizando três dimensões, um fator teve o valor fixado para poder analisar as respostas dos outros dois. Para isto foi considerado o valor do ácido húmico (AH) igual a 0,00; 4,95 e9,90 g kg-1 em todas as equações; dessa forma, objetivou-se entender o efeito do amido, composto hidrofílico, e do ácido esteárico, composto hidrofóbico, e como o ácido húmico exerce influência em ambos.

Para o horizonte A, na análise de estabilidade de agregados via seca, tanto o diâmetro médio ponderado (DMP) quanto o diâmetro médio geométrico (DMG) aumentaram linearmente tanto para oamido quanto para oácido esteárico, sem efeito significativo da interação entre el es (Figuras 1 e 2).

No horizonte $A$, onde o teor de matéria orgânica inicial é mais elevado $\left(3,21 \mathrm{dag} \mathrm{kg}^{-1}\right)$, o efeito dos tratamentos com amido ou áci do esteárico mostrouse significativo para a formação e estabilização dos
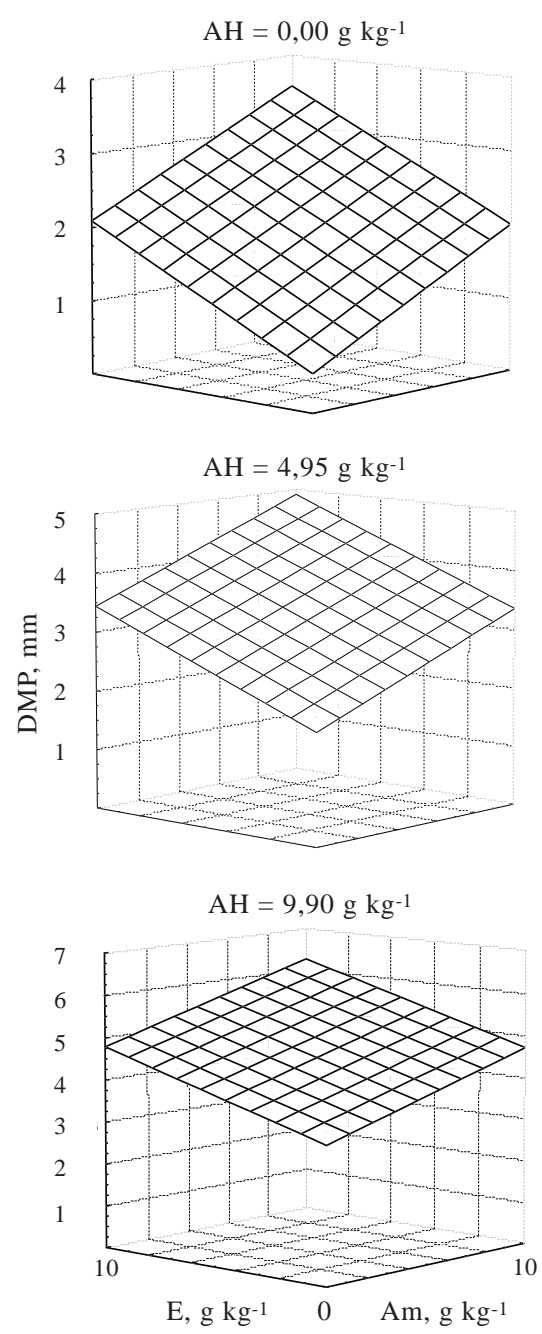

$\mathrm{DMP}=0,5205+0,1487 * \mathrm{Am}+0,1570 * * \mathrm{E}+0,2724 * * * A H$ $R^{2}=0,8040$

Figura 1. Diâmetro médio ponderado (DMP) dos agregados do horizonte $A$ analisado por via seca, considerando a adição de amido (Am) e ácido esteárico (E), para diferentes doses de ácido húmico (AH). 
agregados, sendo tanto maior quanto mais elevada foi a dose do composto utilizado (até $9,90 \mathrm{~g} \mathrm{~kg}^{-1}$ ). Esses resultados foram semel hantes aos obtidos por Chaney \& Swift (1986) que encontraram, com a adição de $0,50 \mathrm{dag} \mathrm{kg}^{-1}$ de glucose, composto hidrofílico, agregação de aproximadamente o dobro no sol o de superfície em relação à do subsolo.

No horizonte $B$, na análise de estabilidade de agregados por via seca, o efeito das variáveis foi quadrático, tanto em DMP quanto em DMG, onde ocorreram as maiores formações de agregados nos valores muito baixos de amido (próximos a zero) e baixos de ácido esteárico (valores no terço inferior do espaço experimental) (Figuras 3 e 4). Esses resultados indicam que, no horizonte $B$, com menor teor de carbono orgânico inicial $\left(0,26{\left.\text { dag } \mathrm{gg}^{-1}\right)}^{2}\right.$ a
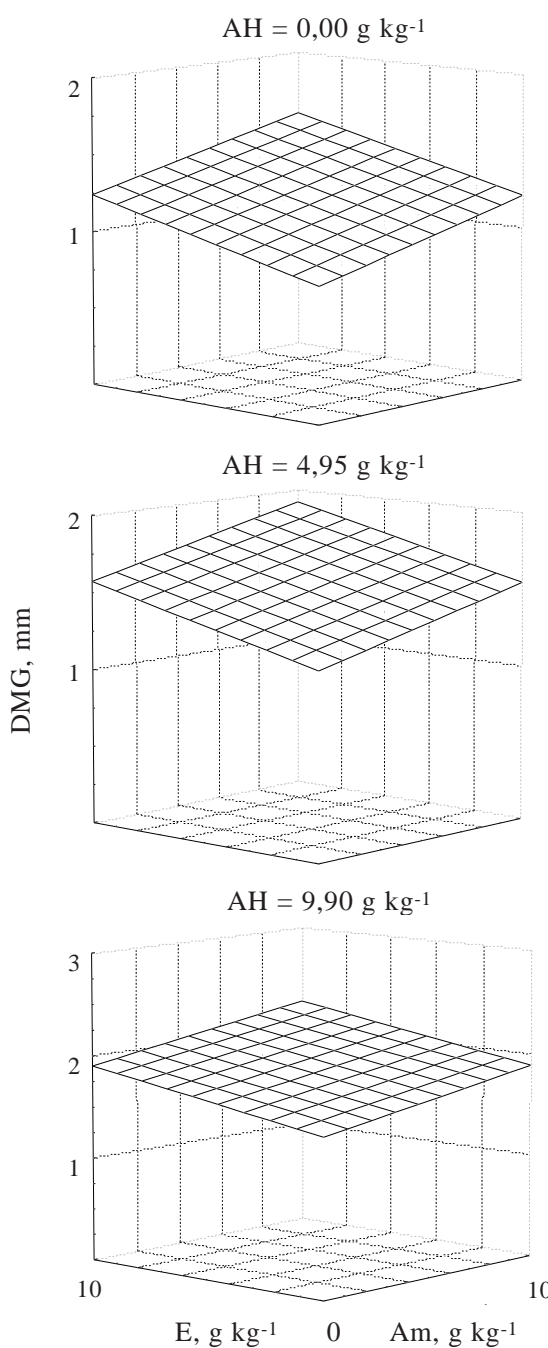

DMG $=0,8651+0,0353 * A m+0,0376 * E+0,0671 * * A H$ $\mathrm{R}^{2}=0,7830$

Figura 2. Diâmetro médio geométrico (DMG) dos agregados do horizonte $A$ analisado por via seca, considerando a adição de amido (Am) e ácido esteárico $(E)$, para diferentes doses de ácido húmico (AH). formação dos agregados não foi muito influenciada pela adição dos compostos orgânicos, decorrentes talvez da elevada concentração de caulinita eóxidos de ferro nesse horizonte (Carvalho Filho, 1989). Essas argilas foram responsáveis pel a estabi lização da maioria dos agregados encontrados nesse solo, tendo os compostos orgânicos adicionados papel secundário.

Oades \& Waters (1991) observaram que, em sol os dominados por óxidos eargila do tipo 1:1, a matéria orgânica não tem papel relevante na agregação. Nestes sol os, ocorrem atrações el etrostáticas entre os óxidos e a superfície da caulinita por causa da existência simultânea de cargas positivas e negativas. No horizonte A, graças ao maior teor de matéria orgânica e redução da interação entre os óxidos e caulinita, fazendo com que a matéria orgânica tenha um papel mais relevantena formação de agregados. I sso pode indicar que, em solos degradados ou com baixo teor de matéria orgânica, a adição de materiais orgânicos pode ter pouca influência ou levar muito tempo para favorecer a formação de agregados.

$\mathrm{Na}$ análise de estabilidade de agregados por via úmi da no horizonte A, ocorreu elevado efeito do ácido esteárico na agregação (Figuras 5, 6e 7). Esse efeito foi quadrático com a maior intensidade nas doses em torno de 5,00 $\mathrm{g} \mathrm{kg}^{-1}$ de áci do esteárico. Segundo Piccolo \& M bagwu (1999), o ácido esteárico tende a aumentar a estabilidade dos agregados por meio da formação de uma cobertura repel ente à água. Essa cobertura se forma graças às ligações hidrofóbicas entre o áci do esteárico e o material orgânico do solo. No mesmo trabalho, os autores, usando um solo arenoso, destacaram que a mel hor dose de resposta para o ácido esteárico foi de 5,00 $\mathrm{g} \mathrm{kg}^{-1}$.

O efeito do ami do nas variáveis DMP eDMG não foi muito intenso, atingindo valores de agregação muito parecidos quando a dose foi de 0,00 ou $9,90 \mathrm{~g} \mathrm{~kg}^{-1}$. Os menores val ores de agregação for am encontrados nas proximidades da dose de $5,00 \mathrm{~g} \mathrm{~kg}^{-1}$. Esses resultados indicam que o composto hidrofílico, dentro do intervalo estudado, não teve papel relevante na formação de agregados. Sendo assim, na curva de resposta do índice de estabilidade de agregados (IEA), obteve-se val or zero, indicando que o amido não teve efeito. Chaney \& Swift (1986) mostraram que um aumento na dose de glucose, composto hidrofílico, da ordem de $150 \%$, teve efeito de $7 \%$ no aumento do DMP dos agregados. Tais autores ainda reforçaram quea glu coseé ineficiente na agregação, quando obtiveram redução no DMP no solo incubado com 5,00 $\mathrm{g} \mathrm{kg}^{-1}$, durante 84 dias.

No horizonte $B$, das variáveis analisadas por via úmida (DMP, DMG e IEA), somente para DMP foram encontrados efeitos significativos (Figura 8). $\mathrm{O}$ uso da dosezero de amido levou à mel hor resposta, como se observou no horizonte A. O ácido esteárico, composto com caráter hidrofóbico mais acentuado, 

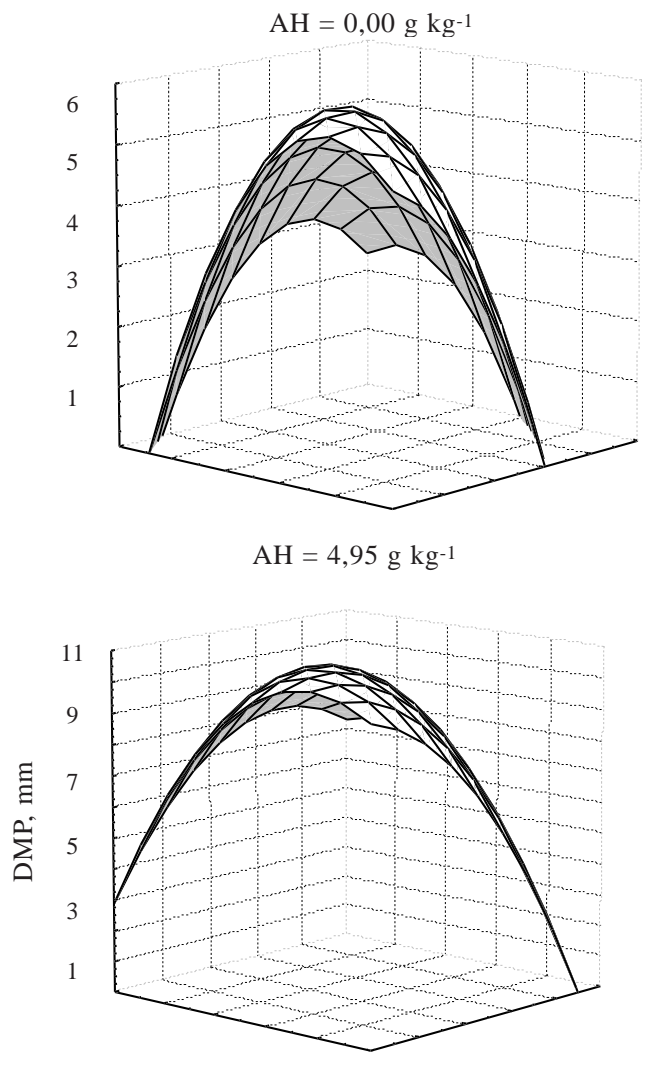

$\mathrm{AH}=9,90 \mathrm{~g} \mathrm{~kg}^{-1}$

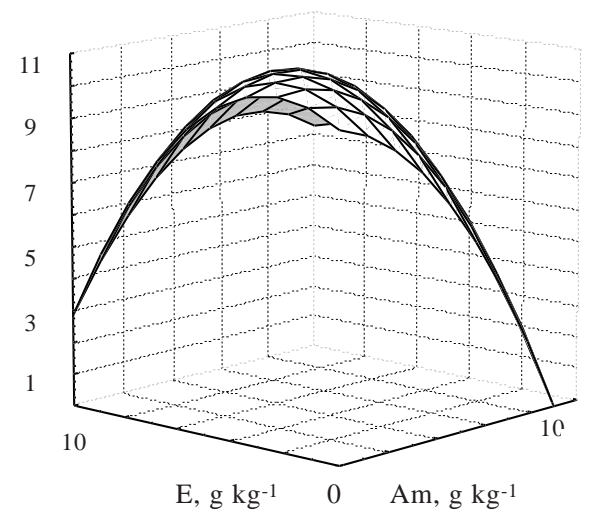

$D M P=5,0057-0,1930^{\text {ns }} A m+0,5979^{n s} \mathrm{E}+1,5186 * * * A H-$ $0,1029^{\circ} A m^{2}-0,1312 * E^{2}-0,1025 * A H^{2}+0,1667 * A m x E$ $\mathrm{R}^{2}=0,6490$

Figura 3. Diâmetro médio ponderado (DMP) dos agregados do horizonte $B$ analisado por via seca, considerando a adição de amido (Am) e ácido esteárico (E), para diferentes doses de ácido húmico (AH).

teve um comportamento parecido, porém mais intenso do que o observado no horizonte $A$. Novamente, a dose de mel hor resposta à agregação deu-se em aproximadamente 5,00 $\mathrm{g} \mathrm{kg}^{-1}$. A queda na agregação deve estar relacionada com o aumento da competição pel os sítios de reação. Dessa forma, as ligações hidrofóbicas ficam enfraquecidas mesmo com el evada concentração de áci do esteárico no meio.
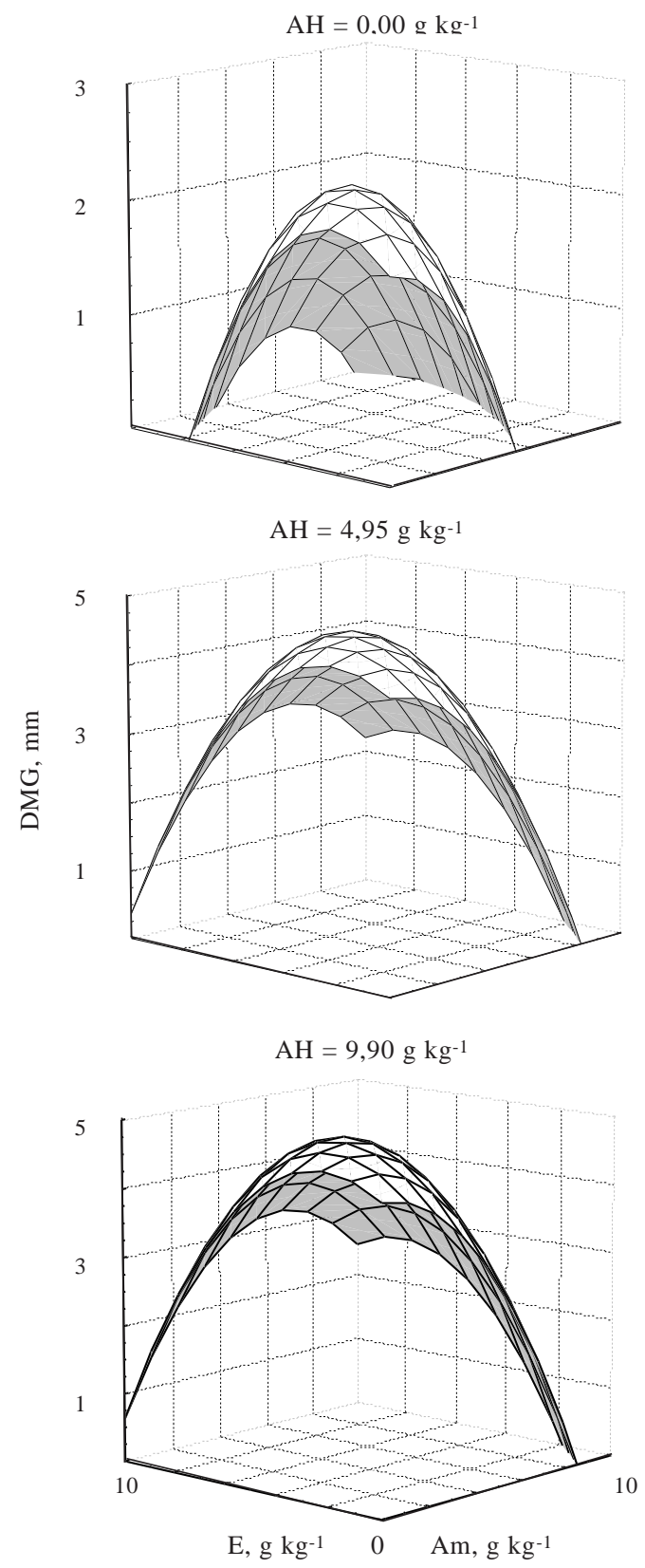

$D M G=1,7571-0,0016^{\text {ns }} A m+0,2823^{\text {ns }} E+0,7017 * * A H-$ $0,0615 * A m^{2}-0,0661 * E^{2}-0,0437 * A H^{2}+0,0801 * A m \times E$ $\mathrm{R}^{2}=0,6750$

Figura 4. Diâmetro médio geométrico (DMG) dos agregados do horizonte $B$ analisado por via seca, considerando a adição de amido (Am) e ácido esteárico $(E)$, para diferentes doses de ácido húmico $(\mathrm{AH})$.

Aumentando a dose do ácido húmico de zero para 4,95 ou para $9,9 \mathrm{~g} \mathrm{~kg}^{-1}$, não há, praticamente, alteração na forma da superfície de resposta (F iguras 1 a 7). Todavia, ocorre el evação dos valores de respostas das variáveis. Isto evidencia que o ácido húmico é capaz de aumentar o tamanho e a estabilidade dos agregados mesmo sendo combinado com um 

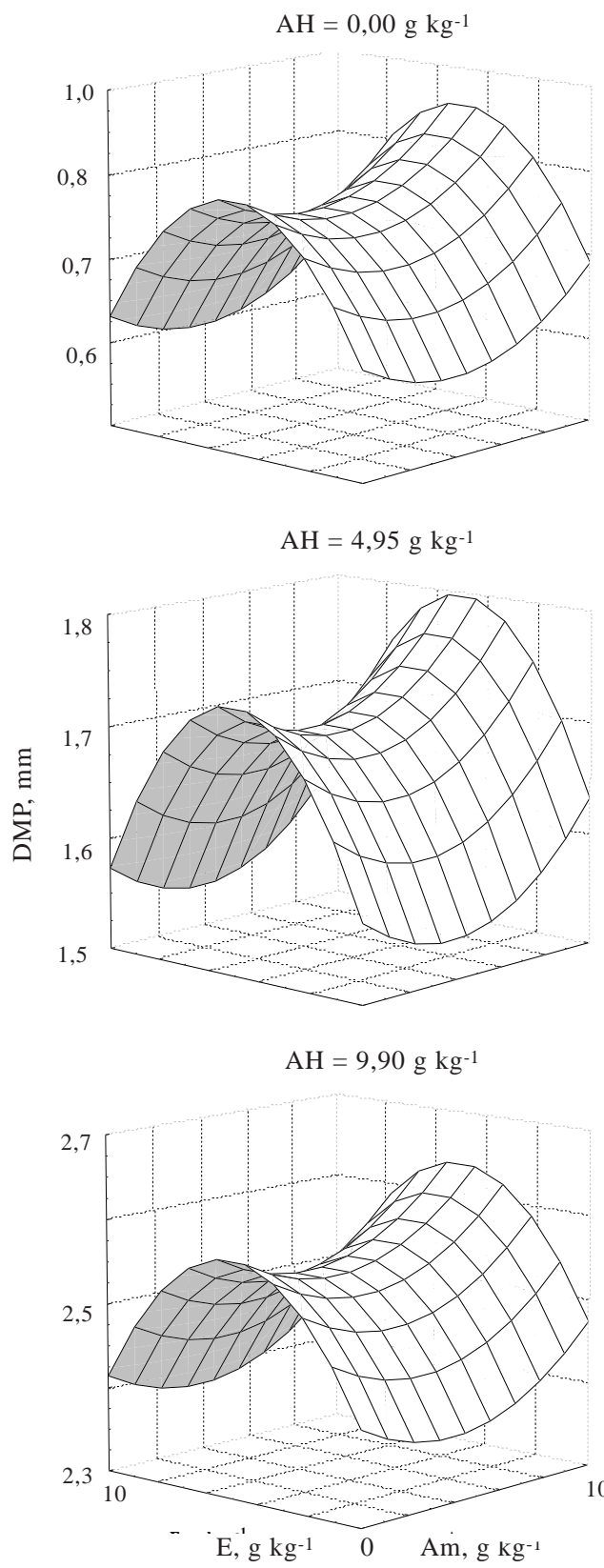

$\mathrm{DMP}=0,7294-0,0189 * \mathrm{Am}+0,0662 * * * \mathrm{E}+0,1700 * * * \mathrm{AH}+$ $0,0025 * * A m^{2}-0,0066 * * * E^{2}$

$\mathrm{R}^{2}=0,8150$

Figura 5. Diâmetro médio ponderado (DMP) dos agregados do horizonte $A$ analisado por via úmida, considerando a adição de amido (Am) e ácido esteárico (E), para diferentes doses de ácido húmico (AH).

composto hidrofílico ou hidrofóbico. Assim, uma molécula com caráter acentuado tanto hidrofóbico quanto hidrofílico, como o ácido húmico, é capaz de aumentar a agregação do solo sem sofrer a influência de outros compostos de maior ou menor grau de hidrofobicidade. Esse efeito pode apresentar uma dose máxima de resposta maior do que $9,90 \mathrm{~g} \mathrm{~kg}^{-1}$.
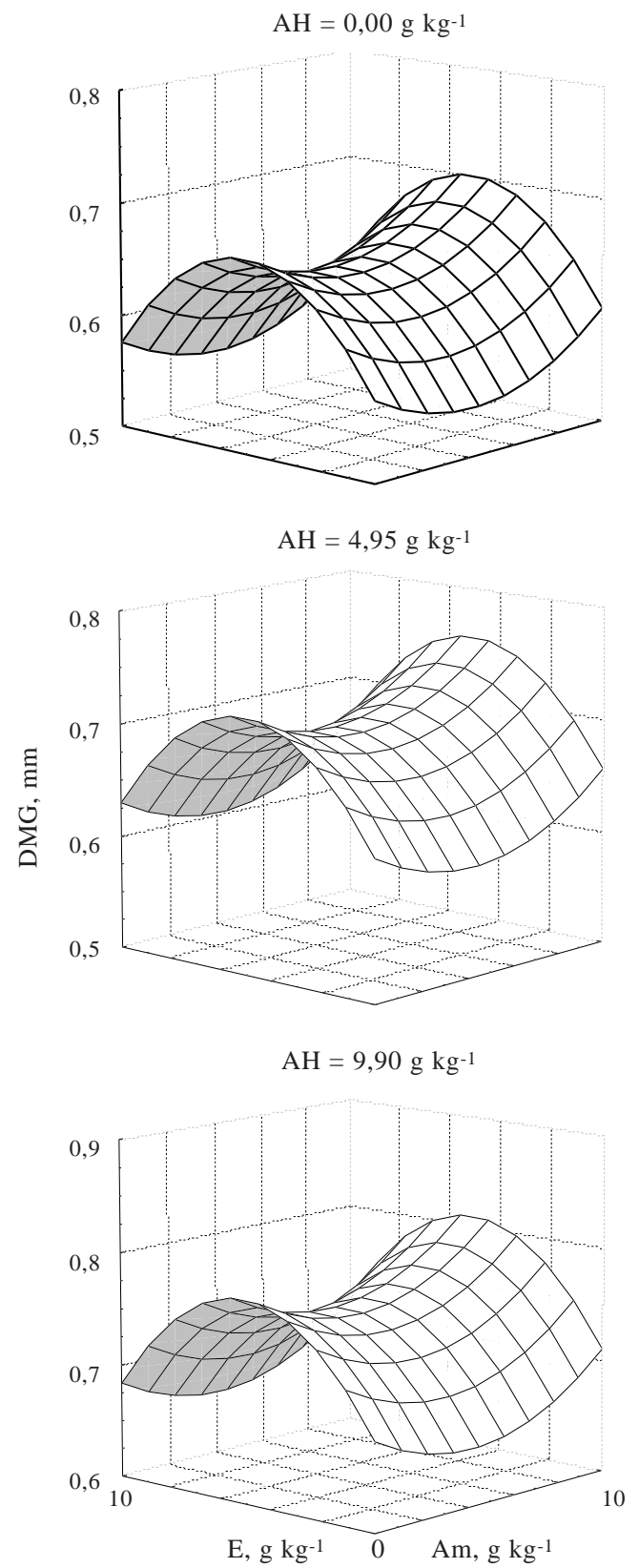

$\mathrm{DMG}=0,5710-0,0139^{\circ} \mathrm{Am}+0,0395^{* * *} \mathrm{E}+0,0109 * * * \mathrm{AH}+$ $0,0017 * \mathrm{AH}^{2}-0,0039 * * * \mathrm{E}^{2}$

$\mathrm{R}^{2}=0,7780$

Figura 6. Diâmetro médio geométrico (DMG) dos agregados do horizonte $A$ analisado por via úmida, considerando a adição de amido (Am) e ácido esteárico (E), para diferentes doses de ácido húmico $(\mathrm{AH})$.

Para avaliar como o ácido húmico atua na estabilização dos agregados do solo, pode-se assumir o valor zero para o amido e para o ácido esteárico em todas as equações de resposta das variáveis analisadas. Para o horizonte $A$, o efeito do ácido húmico é sempre linear e positivo, seja por via seca, seja por via úmi da (Figuras 1, 2, 5, 6 e 7). Dessa forma, qualquer aumento na dose do 

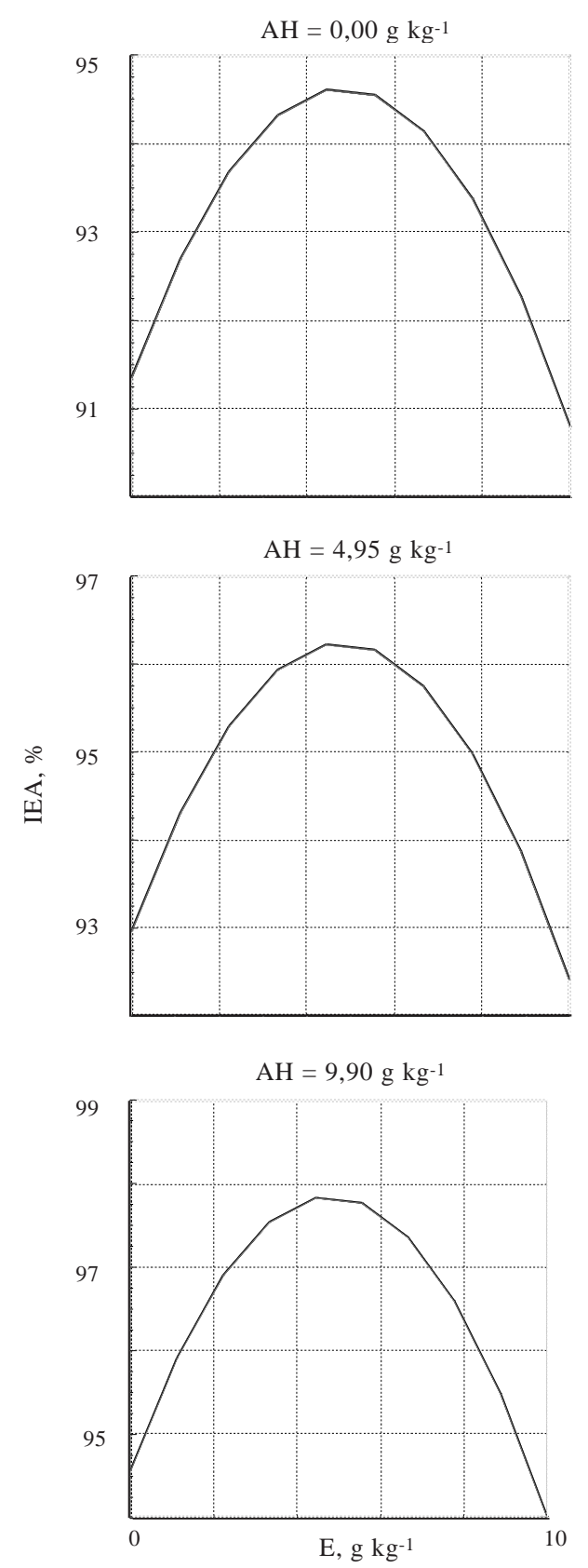

$I E A=91,3552+1,3646 * * E+0,3252 * A H-0,1420 * * E^{2}$ $\mathrm{R}^{2}=0,5220$

Figura 7. Índice de estabilidade de agregados (IEA) dos agregados do horizonte $A$ analisado por via úmida, considerando a adição de ácido esteárico (E), para diferentes doses de ácido húmico (AH).

composto traz resposta direta na melhoria da agregação do sol o dentro do espaço experimental.

Para o horizonte $B$, o efeito do ácido húmico só podeser observado nas variáveis analisadas por via seca, pois o índice de estabilidade de agregados (única variável, por via úmida, que gerou dados significativos para que se construísse um modelo), não contava com o ácido húmico como uma de suas variáveis independentes. I sso pode ter ocorrido, graças à menor densidade de cargas presente nesse horizonte. A CTC efetiva no horizonte B é 12 vezes menor que a do horizonte $A$, isto leva a uma menor interação da fase coloidal com o ácido húmico e, conseqüentemente, com a formação de agregados menos estáveis em água.

Ambos os gráficos de resposta da agregação do horizonte B (Figuras 9 e 10) descrevem uma curva, onde o efeito quadrático foi significativo e evidente. O fenômeno tem efeito positivo atéàs proximidades das doses de 7,50 ou 8,00 $\mathrm{g} \mathrm{kg}^{-1}$, dependendo da variável analisada. Porém, os valores de DMP e DMG do horizonte $B$ são maiores do que os do $A$.

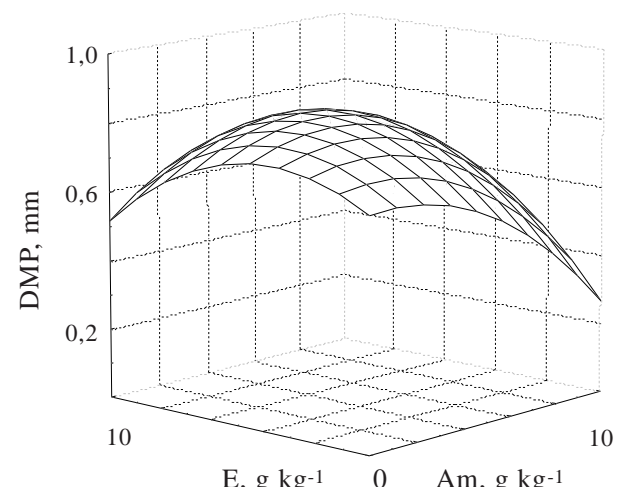

$\mathrm{DMP}=0,6693+0,0098^{\mathrm{NS}} \mathrm{Am}+0,0468 * * \mathrm{E}-0,0050 * A m^{2}-$ $0,0062 * \mathrm{E}^{2}+0,0054^{\circ} \mathrm{Am} \times \mathrm{E}$

$\mathrm{R}^{2}=0,620$

Figura 8. Diâmetro médio ponderado (DMP) dos agregados do horizonte $B$ analisado por via úmida, considerando a adição de amido (Am) e ácido esteárico (E).

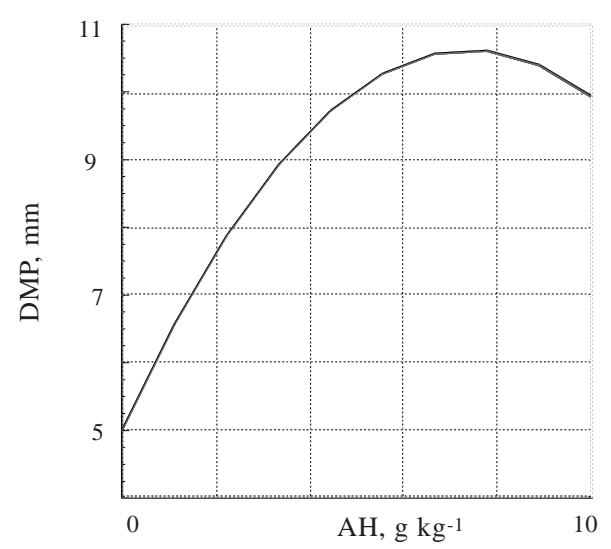

$D M P=5,0057-0,1930^{\text {ns }} A m+0,5979^{\text {ns }} E+1,5186 * * * A H-$ $0,1029^{\circ} A m^{2}-0,1312^{*} E^{2}-0,1025^{*} A H^{2}+0,1667 * A m \times E$ $R^{2}=0,6490$

Figura 9. Diâmetro médio ponderado (DMP) dos agregados do horizonte $B$ analisado por via seca, considerando a adição de ácido húmico $(\mathrm{AH})$, para doses de amido (Am) e ácido esteárico (E) iguais a zero. 


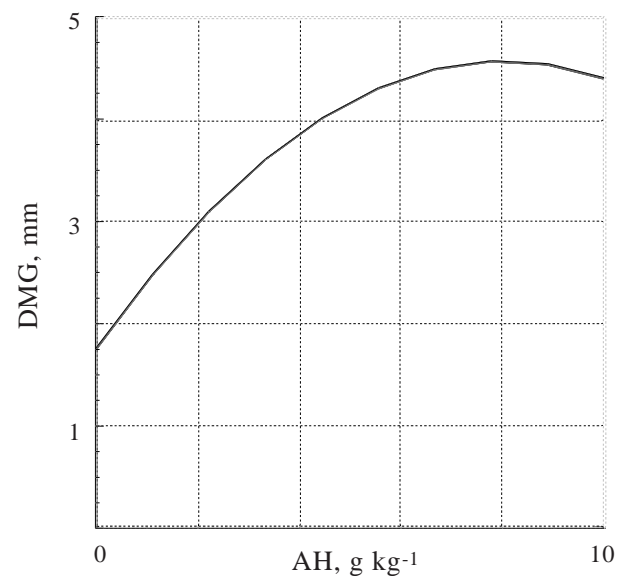

$\mathrm{DMG}=1,7571-0,0016^{\mathrm{ns}} A m+0,2823^{\text {ns }} \mathrm{E}+$ $0,7017 * * A H-0,0615 * A m^{2}-0,0661 * E^{2}-$ $0,0437 * \mathrm{AH}^{2}+0,0801 * A m \times \mathrm{E}$ $\mathrm{R}^{2}=0,6750$

Figura 10. Diâmetro médio geométrico (DMG) dos agregados do horizonte $B$ analisado por via seca, considerando a adição de húmico $(\mathrm{AH})$, para doses de amido (Am) e ácido esteárico (E ) iguais a zero.

\section{CONCLUSÕES}

1. Compostos orgânicos com caráter hidrofílico dominante não tiveram influência na formação e estabilização de agregados do solo, principal mente quando foram usadas doses até $9,9 \mathrm{~g} \mathrm{~kg}^{-1}$.

2. A aplicação de moléculas orgânicas com acentuado caráter hidrofóbico e hidrofílico na sua estrutura, como os ácidos húmicos, foi capaz de melhorar a agregação de solos com grau de intemperismo avançado.

\section{LITE RATURA CITADA}

BOND, R.D. The occurrence of water repellent soils in Australia. In: SYMPOSIUM. WATER REPORT SOILS. Riverside, 1968. Proceedings. Reverside, University of California, Riverside, 1969. p.1-6.

CARVALHO FILHO, A. Caracterização mineralógica, química e física de solos de duas unidades de paisagem do planalto de Viçosa. Viçosa, Universidade Federal de Viçosa, 1989. 114p. (Tese de Mestrado)

CHANEY, K. \& SWIFT, R.S. Studies on aggregate stability. I. Re-formation of soil aggregates. J . Soil Sci., 37:329-335, 1986.

CHENU, C.; BISSONNAIS, Y. \& ARROUAYS, D. Organic matter influence on clay wettability and soil aggregate stability. Soil Sci. Soc. Am. J ., 64:1479-1486, 2000.

CHENU, C.; GUÉRIF, J . \& J AUNET, A.M. Polymer bridging: A mechanism of clay and soil structure stabilization by polysaccharides. In: WORLD CONGRESS OF SOIL SCIENCE, 15., Acal pulco, 1994. World. Acal pulco, Mexico, 1994. p.403-410.
CONTE, P. \& PICCOLO, A. Conformational arrangement of dissolved humic substances. Influence of solution composition on association of humic molecules. Environ. Sci. Technol., 33:1682-1690, 1999.

DINEL, H.; LEVESQUE, M. \& MEHUYS, G.R. Effects of long chain aliphatic compounds on the aggregate stability of a lacustrine silty clay. Soil Sci., 151:228-239, 1991a.

DINEL, H.; LEVESQUE, M.; AMBU, P. \& RIGHI, D. Microbial activity and long-chain aliphatics in the formation of stable soil aggregates. Soil Sci. Soc. Am. J ., 56:1455-1463, 1992.

DINEL, H.; MEHUYS, G.R. \& LEVESQUE, M. Influence of humic and fibric material on the aggregation and aggregate stability of a lacustrine silty clay. Soil Sci., 151:146-158, 1991b.

EMPRESA BRASILEIRA DE PESQUISA AGROPECUÁRIA EMBRAPA. Centro Nacional de Pesquisa de Solos. Manual de métodos de análise de solo. 2.ed. Rio de J aneiro, Ministério da Agricultura e do Abastecimento, 1997. 212p.

FORTUN, A.; BENEYAS, J \& \& FORTUN, C. The effects of fulvic and humic acids on soil aggregation: A micromorphological study. J . Soil Sci., 41:563-572, 1990.

HAYNES, R.J . \& SWIFT, R.S. Stability of soil aggregates in relation to organic constituents and soil water content. J . Soil Sci., 41:73-83, 1990.

J ONGE, L.W.; J ACOBSEN, O.H. \& MOLDRUP, P. Soil water repellency: effects of water content, temperature and particle size. Soil Sci. Soc. Am. J ., 63:437-442, 1999.

KAISER, K. \& ZECH, W. Sorption of dissolved organic nitrogen by acid subsoil horizons and individual mineral phases. Europ. J. Soil Sci., 51:403-411, 2000.

KEMPER, W.D. \& CHEPIL, W.S. Sizedistribution of aggregates. In: BLACK, C.A., ed. Methods of soil analysis. Madison, American Society of Agronomy, 1965. p.449-510.

LYNCH, J .M. \& BRAGG, E. Microorganisms and soil aggregate stability. Adv. Soil Sci., 2:133-171, 1985.

MACGHIE, M. \& POSNER, A.M. Water repellence of a heavy textured western australian surface soil. Aust. J . Soil Res., 18:309-323, 1980.

OADES, J .M. \& WATERS, S.G. Aggregate hierarchy in soils. Aust. J. Soil Res., 29:815-828, 1991.

PICCOLO, A. \& MBAGWU, J.S.C. Effects of different organic wastes amendments on soil microaggregates stability and molecular sizes of humic substances. Plant Soil, 123:2737, 1990.

PICCOLO, A. \& MBAGWU, J.S.C. Humic substances and surfactants effects on the stability of two tropical soils. Soil Sci. Soc. Am. J ., 58:950-955, 1994.

PICCOLO, A. \& MBAGWU, J.S.C. Role of hydrophobic components of soil organic matter in soil aggregate stability. Soil Sci. Soc. Am. J ., 63:1081-1810, 1999.

PICCOLO, A.; NARDI, S. \& CONCHERI, G. Macromolecular changes of humic substances induced by interaction with organic acids. Europ. J. Soil Sci., 47:319-329, 1996.

SULLIVAN, L.A. Soil organic matter, air encapsulation and water stable aggregation. J. Soil Sci., 41:529-534, 1990. 
SWIFT, R.S. Organic matter characterization. In: SPARKS, O.L., ed. Methods of soil analysis Part 3: Chemical methods. Madison, Soil Science Society of America, 1996. p.10111020.

TISDALL, J .M. \& OADES, J .M. Organic matter and waterstable aggregates in soil. J. Soil Sci., 33:141-163, 1982.

TURRENT, F.A. \& LAIRD, R.J . La matriz experimental Plan Pluebla, para ensayos sobre práticas de produccióin de cultivos. Agrociencia, 19:117-143, 1975.
WALLIS, M.G. \& HORNE, D.J . Soil water repellency. Adv. Soil Sci., 20:91-146, 1992.

YOEMANS, J.C. \& BREMNER, J.M. A rapid and precise method for routine determination of organic carbon in soil. Comm. Soil Sci. Plant Anal., 19:1467-1476, 1988.

YODER, R.E. A direct method of aggregate analysis of soil and a study of the physical nature erosion losses. J. Am. Soc. Agric., 28:337-351, 1936 